\title{
CONJUNCTIVAL CHANGES AFTER SUBCONJUNCTIVAL LIGNOCAINE
}

\author{
BAHA N. NOUREDDIN ${ }^{1}$, MICHAEL JEFFREY ${ }^{2}$, WENDY A. FRANKS ${ }^{2}$ and ROGER A. HITCHINGS ${ }^{2}$ \\ Beirut, Lebanon, and London
}

\begin{abstract}
SUMMARY
Subconjunctival injection of $2 \%$ lignocaine at the 12 o'clock position was used as the local anaesthetic in 19 eyes undergoing a primary trabeculectomy for open angle glaucoma. The appearance of the bleb and mean post-operative intraocular pressure (IOP) were compared with those in 29 eyes with the same diagnosis undergoing trabeculectomy under general anaesthesia by the same surgeons over the same time period. The two groups of eyes were similar with regard to treatment with beta blockers $(p>0.1)$, miotics $(p>0.25)$, sympathomimetics $(p>0.25)$, carbonic anhydrase inhibitors $(p>0.5)$, or no treatment $(p>0.25)$. Seventy-seven per cent of the local anaesthetic group and $25 \%$ of the general anaesthetic group developed avaseular, thin-walled drainage blebs $(p<0.001)$. The mean post-operative IOP was significantly lower in the group receiving local anaesthetic $(p<0.001)$. The reasons for and significance of these observations are discussed, and the merits and disadvantages of thin-walled blebs are evaluated.
\end{abstract}

Trabeculectomy lends itself to a local anaesthetic: the operation is short, the patients elderly, and anaesthesia is readily achieved. Retrobulbar anaesthesia carries with it some hazards: retrobulbar haemorrhage, injury to the optic nerve sheath or penetration of the globe. ${ }^{1}$ In addition, glaucoma patients undergoing retrobulbar anaesthesia may be aware of a temporary blurring of their vision as a result of the local anaesthetic interfering with nerve conduction. Usually the effect is transient, but for uniocolar patients, and those with severe glaucomatous loss in particular, this effect can be worrying to patient and surgeon alike.

In an attempt to overcome these problems and continue using local anaesthesia, we and other authors ${ }^{2}$ adopted a technique of subconjunctival injections of $2 \%$ lignocaine. The injection was placed beneath the bulbar conjunctiva,

From: ${ }^{1}$ Eye Department, American University of Beirut, Lebanon; ${ }^{2}$ Glaucoma Unit, Moorfields Eye Hospital, London, UK.

Correspondence to: Mr. Roger A. Hitchings, FRCS, Moorfields Eye Hospital, City Road, London EC1V 2PD, UK. sufficient to raise a bleb at the limbus and to infiltrate the tendon of the superior rectus muscle producing conjunctival and episcleral sensory loss. This limited anaesthetic proved quite sufficient, for the sclera has a restricted sensory nerve supply while innervation of the iris is limited to a few sensory twigs running forwards from the ciliary body plexus. Provided that care was taken not to pull on the iris root, an iridectomy causes no pain. We found that this subconjunctival anaesthetic was so successful that we increasingly employed it as a means of anaesthesia in trabeculectomy surgery, until such time that one of us (M.J.) noted an increased incidence of avascular fistulising blebs appearing in the first post-operative months. Concerned that this could be related to the local anaesthetic, we reviewed all cases operated on during the period when subconjunctival anaesthesia was used.

\section{PATIENTS AND METHODS}

All patients who underwent trabeculectomy by the Glaucoma Unit at Moorfields Eye Hospital, in a 6-month period were retrospectively reviewed. Patients who had their filtering surgery combined with cataract extraction and those who were lost to follow-up were excluded.

Age, sex, diagnosis, type of medical treatment, number of previous operations and pre-operative intraocular pressures were recorded. The indication for filtering surgery was uncontrolled intraocular pressure (IOP) or progressive visual field loss on maximally tolerated medical therapy. A group of 5 patients had had their surgery as primary treatment. The decision to perform glaucoma surgery under local anaesthesia was based on two factors: if the patient was not considered fit enough for a general anaesthetic or was undergoing day case surgery. The state of the eye, IOP control or extent of the visual field loss played no part in case selection for a local or a general anaesthetic.

The local anaesthetic consisted of a subconjunctival injection beneath the bulbar conjunctiva, centred at the 12 o'clock position, of $2 \mathrm{ml} 2 \%$ plain lignocaine (without an added sympathomimetic). This caused upward ballooning of the conjunctiva. The lignocaine extended 


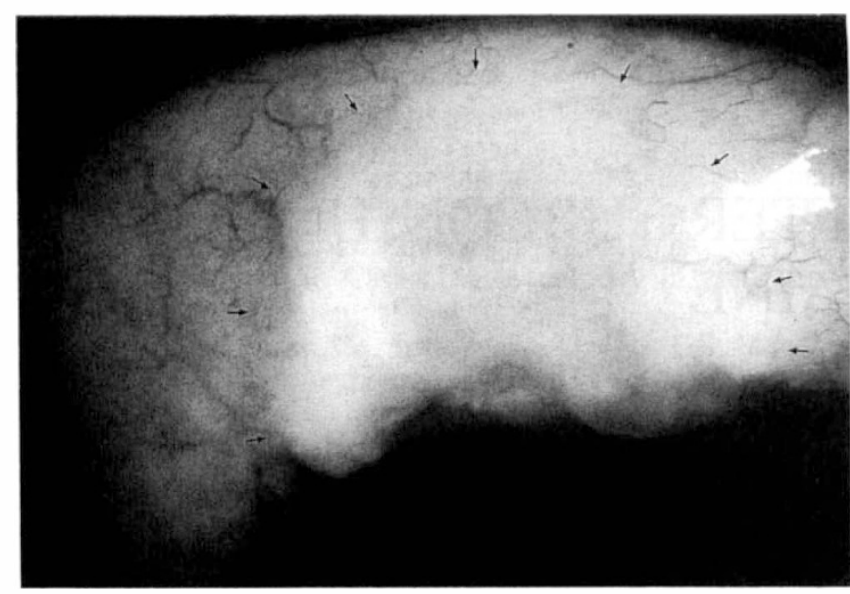

Fig. 1. Thick-walled bleb (arrows).

superiorly towards the superior rectus insertion and laterally towards the 10 o'clock and 2 o'clock positions. Five minutes after the injection the operation was commenced by putting a 6-0 silk superior rectus traction suture. The anaesthetic was supplemented with topical amethocaine drops. The alternative was a general anaesthetic without any conjunctival or retrobulbar anaesthesia.

In all cases the operation was a standard trabeculectomy beneath a fornix-based flap. The conjunctival and scleral flaps were each sutured with two or three 10-0 monofilament nylon sutures. Subconjunctival cefuroxime and dexamethasone were given at the end of the operation. Post-operatively, topical dexamethasone and chloromycetin drops were administered for 6 and 2 weeks respectively.

The outcome of surgery in terms of IOP control was noted at each visit. Success was defined as a consistent post-operative IOP of less than $21 \mathrm{mmHg}$ not requiring any medical treatment. The appearance of the filtering bleb was categorised at each visit as flat or raised and, if raised, as either thin-walled or thick-walled (Figs. 1 and 2). (The term 'flat' was used to describe a bleb not considered to rise above the surface of the surrounding conjunctiva; 'raised' was the opposite. 'Thin-walled blebs' had translucent walls permitting visualisation of the underlying structures, while 'thick-walled blebs' were opaque.)

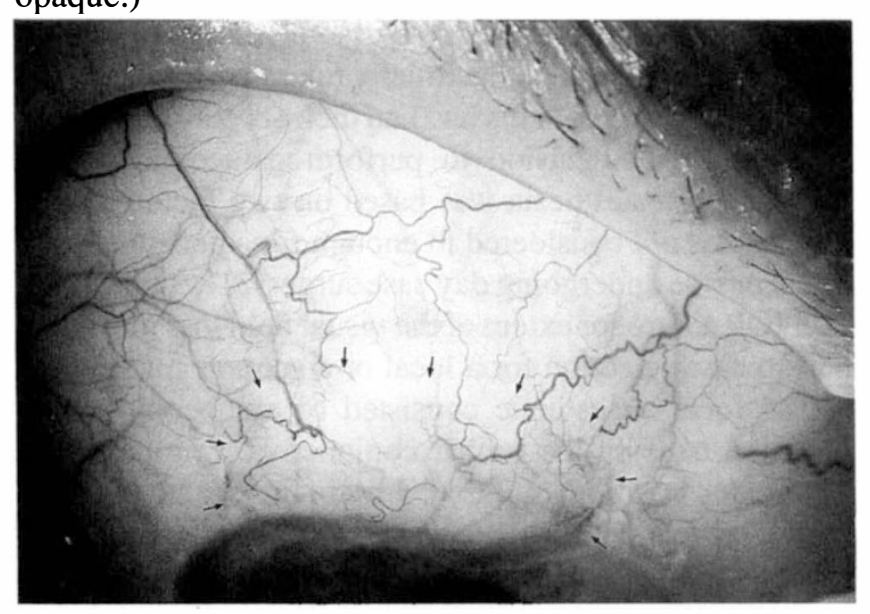

Fig. 2. Raised, thin-walled, translucent cystic bleb (arrows).
Table I. Diagnosis of patients in the general and local anaesthesia groups

\begin{tabular}{lcc}
\hline Diagnosis & GA group & LA group \\
\hline POAG & 28 & 17 \\
LTG & 1 & 2 \\
Total & 29 & 19 \\
\hline
\end{tabular}

GA, general anaesthesia; LA, local anaesthesia; POAG, primary open angle glaucoma; LTG, low tension glaucoma.

Statistical analysis of IOP was done using the method of comparison of means. ${ }^{3}$ Analysis of bleb appearance was done using the chi-squared test for fourfold tables. ${ }^{4}$

\section{RESULTS}

For the purposes of this review only patients with primary open angle glaucoma (POAG), including low tension glaucoma (LTG), undergoing trabeculectomy were analysed. There were 29 patients in the general anaesthesia (GA) group and 19 patients in the local anaesthetic (LA) group (Table I). The mean age of the GA group was 56.30 (SD 16.20) years with a range of 38-79 years, while that of the LA group was 61.28 (SD 13.10) years with a range of $42-80$ years. The male to female ratio was 19 to 10 in the GA group and 12 to 7 in the LA group.

All patients had satisfactory IOP control during the mean follow-up of 11.60 months in the GA group (range 9-15 months) and of 10.95 months in the LA group (range 9-15 months).

The type of medical treatment in both groups is shown in Fig. 3, while Fig. 4 shows the distribution of the blebs in the two groups as being thick-walled, thin-walled or flat. None of the patients had post-operative 5-fluorouracil subconjunctival injections.

Seven (25\%) of the patients in the GA group developed thin-walled blebs with positive Seidel tests, compared with $13(77 \%)$ of the LA patients. Statistical analysis showed a highly significant difference in the incidence of thin-walled cystic blebs in the two groups $(p<0.001)$. The same analysis showed no significant difference between the groups with respect to treatment with beta blockers $(p>0.1)$, miotics $(p>0.25)$, sympathomimetics $(p>0.25)$, carbonic anhydrase inhibitors $(p>0.5)$ or with respect to no treatment $(p>0.25)$ (Fig. 3).

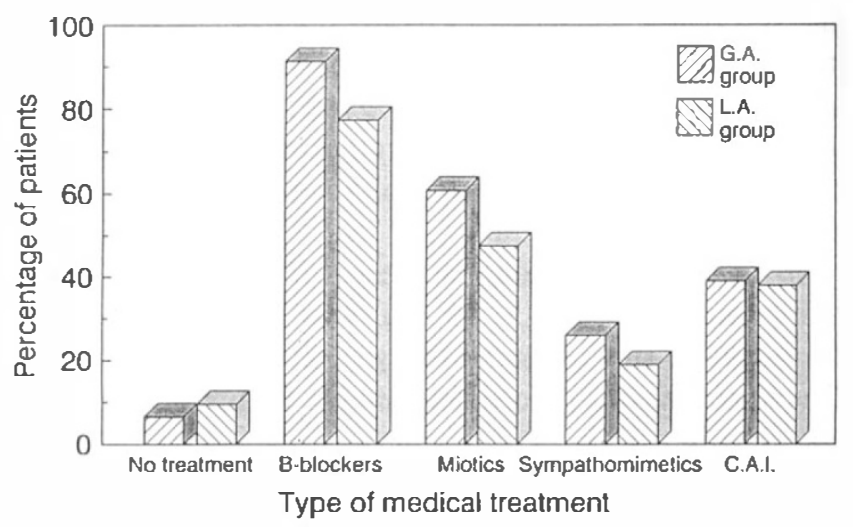

Fig. 3. Percentage of patients on specific medical treatment in each of the two groups. GA, general anaesthesia; LA, local anaesthesia; CAI, carbonic anhydrase inhibitors. 


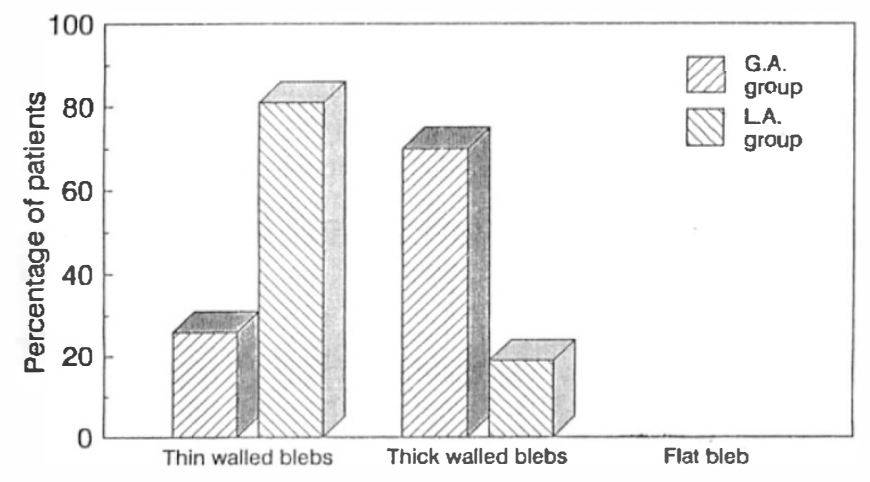

Fig. 4. Patients categorised in terms of the type of bleb they developed.

Table II shows the pre-operative IOPs in the two groups to be rather similar $(p>0.5)$, and the post-operative IOPs to be significantly lower in the LA group $(p<0.0027)$. Similarly, Table III shows that despite similar pre-operative IOPs in eyes that developed thin- and thick-walled blebs (within the GA group) $(p>0.25)$, the post-operative IOPs were significantly lower in patients with thin-walled blebs $(p<0.001)$. Statistical analysis of any IOP difference can not be done in the LA group, as the vast majority (77\%) had thin-walled blebs.

\section{DISCUSSION}

Several microsurgical operations on the trabeculum have been devised to increase the facility of outflow (e.g. trabeculotomy, ${ }^{5,6}$ sinusotomy. ${ }^{7}$ Full-thickness sclerostomies were also popular for some time. ${ }^{8}$ Trabeculectomy, however, is most popular, giving a combination of good IOP control $^{9-13}$ and a lower incidence of complications. ${ }^{14-16}$ Some authors are currently advocating trabeculectomy as a primary approach in treating open angle glaucoma. ${ }^{17}$

The formation of an elevated subconjunctival drainage bleb is the earliest sign of success of trabeculectomy. ${ }^{10}$ Functional blebs have been described as being either thick-walled or thin-walled. ${ }^{18}$ Thick-walled blebs are relatively flat, pale, with visible vascularisation and do not encroach on the limbus. They have a negative Seidel test and mainly provide subconjunctival drainage. ${ }^{19}$ On the other hand, thin-walled blebs are elevated cysts containing many septae and reach the limbus. The majority have a positive Seidel test with mainly transconjunctival drainage. ${ }^{20-22}$ They are usually accompanied by lower IOP and some surgeons believe they last longer. ${ }^{23}$ Some reports commented on an association with old age and metabolic disease. $^{18}$

Histologically, the cystic spaces in thin blebs corre-

Table II. Pre- and post-operative IOPs in the general and local anaesthesia groups

\begin{tabular}{lccccc}
\hline & \multicolumn{2}{c}{ Pre-operative IOP $(\mathrm{mmHg})$} & & Post-operative IOP $(\mathrm{mmHg})$ \\
\cline { 2 - 3 } \cline { 5 - 6 } \cline { 5 - 6 } & Mean & $\mathrm{SD}$ & & Mean & $\mathrm{SD}$ \\
\hline GA group & 25.95 & 2.69 & & 15.05 & 2.92 \\
LA group & 25.51 & 2.73 & & 12.68 & 1.43 \\
& \multicolumn{2}{c}{$\mathrm{p}>0.5$} & & \multicolumn{2}{c}{$\mathrm{p}<0.0027$} \\
\hline
\end{tabular}

Table III. Pre- and post-operative IOPs in patients with thin-walled and thick-walled blebs

\begin{tabular}{lccccc}
\hline & \multicolumn{2}{c}{ Pre-operative IOP $(\mathrm{mmHg})$} & & \multicolumn{2}{c}{ Post-operative IOP $(\mathrm{mmHg})$} \\
\cline { 2 - 3 } \cline { 5 - 6 } \cline { 5 - 6 } & Mean & $\mathrm{SD}$ & & Mean & $\mathrm{SD}$ \\
\hline Thin blebs & 24.71 & 2.41 & & 12.00 & 1.46 \\
Thick blebs & 25.93 & 2.85 & & 16.19 & 2.42 \\
& \multicolumn{2}{c}{$\mathrm{p}>0.1$} & & \multicolumn{2}{c}{$\mathrm{p}<0.001$} \\
\hline
\end{tabular}

spond to a loosely arranged subepithelial connective tissue. The latter is thicker and denser, containing collagen, fibroblasts and blood vessels in the thick-walled blebs. ${ }^{19}$ Unfortunately, thin-walled blebs are more vulnerable to infection. ${ }^{18,23,24}$

This retrospective review has demonstrated good shortterm results following trabeculectomy in eyes with open angle glaucoma undergoing a first-time fistulising procedure. The two groups differed in the anaesthetic technique employed. They were operated on by the same surgeons using the same operative technique over the same period. The criteria for success were whether the IOP stayed below $21 \mathrm{mmHG}$ without additional antiglaucoma treatment. These two groups of patients were found to differ in one respect during the post-operative period: the appearance of the fistulising bleb. Those eyes which had had subconjunctival anaesthesia were much more likely to develop cystic changes in the conjunctiva over the sclerostomy. This change developed comparatively rapidly, more than $80 \%$ of these eyes having it by 11 months post-operatively. Of interest also is the association of these thin blebs with lower IOPs despite similar preoperative IOPs $[p<0.0027$ (Table II) and $p<0.001$ (Table III)].

It is not clear why subconjunctival lignocaine might contribute to the formation of thin-walled blebs. We speculate that it might have an inhibitory effect on fibroblasts, hence preventing the formation of subepithelial connective tissue. The local action of lignocaine on fibroblasts in tissue culture is currently being studied.

Key words: Blebs, Lignocaine, Open angle glaucoma, Trabeculectomy.

\section{REFERENCES}

1. Morgan CM, Schatz H, Vine AK, et al. Ocular complications associated with retrobulbar injections. Ophthalmology 1988;95:660-5.

2. Furuta M, Toriumi T, Kashiwagi K, Susuno S. Limbal anaesthesia for cataract surgery. Ophthalmic Surg 1990;21:22-5.

3. Armitage P. Statistical methods in medical research. Oxford: Blackwell Scientific, 1971.

4. Fisher RA, Yates F. Statistical tables for biological, agricultural and medical research. Harlow: Longman, 1974.

5. Strachan IM. A method of trabeculectomy with some preliminary results. Br J Ophthalmol 1967;51:539-46.

6. Smith $\mathrm{R}$. The comparison between a group of drainage operations and trabeculectomy, after a follow-up of five years. Trans Ophthalmol Soc UK 1969;89:511-5.

7. Krasnov MM. Externalization of Schlemm's canal (sinusotomy) in glaucoma. Br J Ophthalmol 1968;52:157-61.

8. Scheie H. Filtering operations for glaucoma. Am J Ophthalmol 1963;53:571-90.

9. Watson P. Trabeculectomy: a modified ab externo technique. Ann Ophthalmol 1970;2:199-205. 
10. Thyer HW, Wilson P. Trabeculectomy. Br J Ophthalmol 1972;56:37-40.

11. Cairns JE. Trabeculectomy: preliminary report of a new method. Am J Ophthalmol 1968;66:673-9.

12. Wilson P. Trabeculectomy: long term follow-up. Br J Ophthalmol 1977;61:535-8.

13. Jay JL, Murray SB. Characteristics of reduction of intraocular pressure after trabeculectomy. $\mathrm{Br} \mathrm{J}$ Ophthalmol 1980;64:432-5.

14. Shields MB. Trabeculectomy vs. full thickness filtering operation for glaucoma. Ophthalmic Surg 1980;11: 498-505.

15. Spaeth GL. A prospective, controlled study to compare the Scheie procedure with Watson's trabeculectomy. Ophthalmic Surg 1980;11:688-94.

16. Singh G. Trabeculectomy, Scheie's operation in chronic simple glaucoma. Glaucoma 1981;3:264-8.

17. Jay JL, Murray SB. Early trabeculectomy versus conven- tional management in primary open angle glaucoma. $\mathrm{Br} \mathbf{J}$ Ophthalmol 1988;72:881-9.

18. Mattenhauer JM, Lipsich MP. Late endophthalmitis after filtering surgery. Am J Ophthalmol 1971;72:1097-101.

19. Schwartz AL, Anderson DL. Trabecular surgery. Arch Ophthalmol 1974;92:134-8.

20. Addicks EM, Quigley HA. Histologic characteristics of filtering blebs in glaucomatous eyes. Arch Ophthalmol 1983;101:795-8.

21. D'Ermo F, Bonomi L. Trabeculectomy: results in the treatment of glaucoma. Ophthalmologica 1973;166:311-20.

22. Ritch R, Shields MB, Krupin T. The glaucomas, 1st ed. St Louis: CV Mosby, 1989:637-43.

23. Hoskins HD, Kass M. Becker-Shaffer's diagnosis and treatment of the glaucomas, 6th ed. St Louis: CV Mosby, 1989:598-607.

24. Lobue TD, Deutsch TA, Stein RM. Moraxella nonliquefaciens endophthalmitis after trabeculectomy. Am J Ophthalmol 1985;99:343-5. 